\title{
Realising the long-term promise of insulin therapy: the DCCT/EDIC study
}

\author{
David M. Nathan ${ }^{1}$
}

Received: 5 October 2020 / Accepted: 4 November 2020 / Published online: 6 February 2021

(C) The Author(s), under exclusive licence to Springer-Verlag GmbH, DE part of Springer Nature 2021

\begin{abstract}
The introduction of insulin in the treatment of juvenile-onset, now type 1, diabetes mellitus transformed a rapidly fatal disease into a chronic degenerative one. During the insulin-treatment era, long-term microvascular and cardiovascular complications proved to be the bane of existence for people with type 1 diabetes, leading to blindness, kidney failure, amputations, cardiovascular disease (CVD) and premature mortality. The nascent understanding of the link between non-physiologically regulated glucose levels and these complications led to the development of new treatment tools in the 1970s and 1980s that facilitated the delivery of insulin to achieve glucose levels closer to non-diabetic levels. These therapeutic advances set the stage for definitive testing of the glucose hypothesis. The Diabetes Control and Complications Trial (DCCT), supported by the National Institute of Diabetes Digestive and Kidney Diseases, National Institutes of Health $(\mathrm{NIH})$, definitively established the benefits and risks of intensive therapy that substantially lowered mean blood glucose levels, measured by $\mathrm{HbA}_{1 \mathrm{c}}$, over a mean 6.5 years of therapy. Intensive therapy in the DCCT, resulting in a mean $\mathrm{HbA}_{1 \mathrm{c}}$ of $\sim 7 \%(53 \mathrm{mmol} / \mathrm{mol})$, reduced the development and progression of early microvascular and neurological complications associated with diabetes by 34-76\% compared with the conventional-treatment group, which maintained an $\mathrm{HbA}_{1 \mathrm{c}}$ of $\sim 9 \%$ ( $\left.75 \mathrm{mmol} / \mathrm{mol}\right)$. Intensive therapy was also associated with weight gain and a threefold increased risk for hypoglycaemia. At the end of the DCCT, a long-term observational follow-up study, the Epidemiology of Diabetes Interventions and Complications (EDIC) study, commenced. Despite the convergence of $\mathrm{HbA}_{1 \mathrm{c}}$ levels between the two groups during EDIC, owing to the adoption of intensive therapy by the original DCCT conventional-treatment group and the return of all participants to their own healthcare providers for diabetes care, the development and progression of complications continued to be substantially less in the original intensive-treatment group vs the conventional-treatment group; this phenomenon was termed 'metabolic memory'. The DCCT demonstrated a major reduction in early-stage complications with intensive therapy and the metabolic memory phenomenon during EDIC contributed to a substantially lower burden of advanced complications over time. These included a 57\% lower risk of CVD events and 33\% lower rate of mortality in the original intensive-treatment group compared with the conventional-treatment group. DCCT/EDIC has ushered in the intensive-treatment era, which has been universally adopted and includes the goal of achieving $\mathrm{HbA}_{1 \mathrm{c}}$ levels less than $7 \%(53 \mathrm{mmol} / \mathrm{mol})$ for most patients. Although the challenge of making intensive therapy (with the aim of achieving normoglycaemia) as widely accessible and safe as possible remains, continuing improvements in insulin therapy 100 years after its introduction promise a brighter future for people with type 1 diabetes.
\end{abstract}

Keywords Control and complications $\cdot \mathrm{HbA}_{1 \mathrm{c}}$ and complications $\cdot$ Hypoglycaemia $\cdot$ Intensive therapy $\cdot$ Long-term diabetic complications $\cdot$ Metabolic memory $\cdot$ Review $\cdot$ Type 1 diabetes

\section{Abbreviations \\ CSII Continuous subcutaneous insulin infusion \\ DCCT Diabetes Control and Complications Trial}

David M. Nathan

dnathan@mgh.harvard.edu

1 Diabetes Center, Massachusetts General Hospital, Harvard Medical School, Boston, MA, USA
EDIC Epidemiology of Diabetes Interventions and Complications

ETDRS Early Treatment Diabetic Retinopathy Study

MDI Multiple daily injection

NIDDK National Institute of Diabetes Digestive and Kidney Diseases

QoL Quality of life

SMBG Self-monitoring of blood glucose 


\section{Introduction}

The introduction of insulin 100 years ago [1] transformed what we now call type 1 diabetes mellitus from a rapidly fatal disease to a chronic degenerative one. In the first 20-30 years of insulin therapy, long-term complications, previously unknown owing to the brief lifespan of patients in the preinsulin era, began to emerge. Those complications affected the microvasculature of the eyes and kidneys and the autonomic and peripheral nervous system, and amplified risk for cardiovascular disease (CVD) and peripheral arterial disease. They resulted in severe morbidity and shortened the lifespan of individuals with 'juvenile-onset' diabetes, as type 1 diabetes was called until 1979 [2]. The Steno Hospital (Copenhagen, Denmark) experience over the first 40 years of insulin therapy revealed that of their 307 patients diagnosed before 1931 and before age 31, 30\% were blind or had severely impaired vision, $22 \%$ had developed renal failure, $12 \%$ had gangrene or amputations, and $21 \%$ had suffered myocardial infarction and $10 \%$ stroke [3]. Mortality was two- to sixfold higher than that of an age- and sex-matched non-diabetic population.

In the setting of insulin therapy, these long-term complications posed the greatest risk to the health of patients with type 1 diabetes and there was endless debate regarding their cause. Some proponents considered the complications as unalterable accompaniments of diabetes, perhaps genetically mediated [4], while others concluded that the microvascular complications were intimately related to hyperglycaemia [5]. The introduction of an accurate and objective measurement of chronic blood glucose levels, the $\mathrm{HbA}_{1 \mathrm{c}}$ assay, permitted, for the first time, a reliable examination of the association of hyperglycaemia and retinopathy [6], considered the most diabetes-specific complication. In addition to the $\mathrm{HbA}_{1 \mathrm{c}}$ assay, the development of another critical clinical tool, self-monitoring of blood glucose (SMBG), facilitated insulin delivery that more closely resembled normal insulin secretion with multiple daily injection (MDI) regimens and continuous subcutaneous insulin infusion (CSII) with insulin pumps [7]. These new treatment methods held the promise of achieving glucose levels closer to normoglycaemia. All of these developments came together in the late 1970s and early 1980s, almost 60 years after the discovery of insulin, setting the stage to test the 'glucose hypothesis' of diabetes complications; specifically, that hyperglycaemia was the cause of diabetes complications. Several small, relatively brief and under-powered clinical trials established the ability to create glycaemic separation in populations with type 1 diabetes, but demonstrated no effect, or even short-term worsening, of lower blood glucose levels on retinopathy $[8,9]$ as often as they demonstrated small improvements in microvascular complications $[10,11]$.

\section{History of the Diabetes Control and Complications Trial}

The clinical trial that became the Diabetes Control and Complications Trial (DCCT) was brought about through the National Diabetes Advisory Board Act, mandated by the US Congress and championed by Congressman Tim Lee Carter, the only physician in the US House of Representatives, and Senator Richard Schweiker. The Act (Public Law 93-354) established the US National Commission on Diabetes, which, in its 'Long Range Plan to Combat Diabetes' [12], proposed a '5-year study to assess the effect of treatment of juvenile-onset diabetes on the development of micro- and macrovascular complications'. The proposed study was reconsidered by the National Institutes of Health (NIH) Diabetes Mellitus Coordinating Committee in their 1979 report on 'Progress Towards Implementation of the Recommendations of the National Commission on Diabetes and the National Diabetes Advisory Board' [13]. They noted that a study to determine 'the feasibility of creating two groups of diabetic patients differing significantly in their blood glucose concentrations as the results of "tight" vs. "customary treatment regimens" needed to consider the "significant and ongoing advances in potential methods for treating the metabolic aspects of diabetes mellitus'. It was not until 1981 that the National Institute of Arthritis, Diabetes and Digestive and Kidney Diseases (NIADDK), which later became the National Institute of Diabetes Digestive and Kidney Diseases (NIDDK), issued requests for applications to recruit clinical centres and a data coordinating centre (Fig. 1). The study was to determine the answers to the following questions: (1) will an intensive treatment programme prevent or delay the appearance of early background retinopathy?; and (2) will such an intervention prevent the progression of early retinopathy to more advanced forms of retinopathy?

The original 21 clinical centres (19 in the US and two in Canada) and the data coordinating centre located at the George Washington University (Washington, DC, USA), were all selected competitively through peer review and planned the DCCT under the leadership of Oscar Crofford, MD, who had chaired the National Commission on Diabetes. After almost 18 months of planning, the feasibility study was launched in 1983. It studied 278 volunteers, including 87 adolescents, and was successfully completed in 1985 [14]. The feasibility phase demonstrated the ability to recruit eligible participants in a timely fashion, implement the conventional (originally called 'standard') and intensive ('experimental') treatments in the randomly assigned groups, and separate $\mathrm{HbA}_{1 \mathrm{c}}$ by approximately $2 \%(22 \mathrm{mmol} / \mathrm{mol})(8.88 \%$ vs $7.03 \%$ [74 vs $53 \mathrm{mmol} / \mathrm{mol}]$ in the conventional- vs intensive-treatment group). The full-scale trial, with six clinical sites added to the original 21 , subsequently recruited a total of 1441 eligible participants between 1986 and 1989 into the 
Fig. 1 Timeline of the DCCT and its long-term follow-up EDIC study. RFA, research funding announcement. (C) American Diabetes Association 2013, adapted from [49]. Copyright and all rights reserved. Material from this publication has been used with the permission of the American Diabetes Association. This figure is available as part of a downloadable slideset

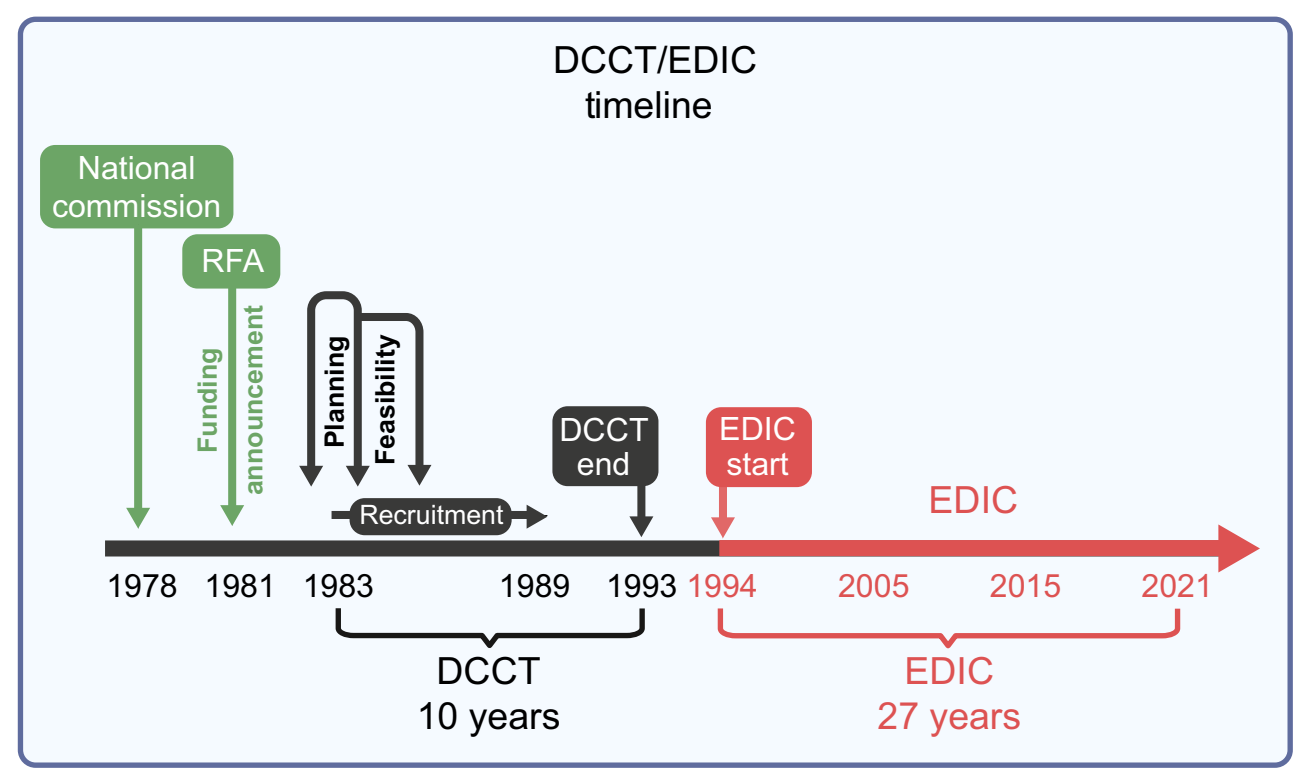

primary prevention and secondary intervention cohorts [15]. A summary of baseline characteristics of the participants is shown in Table 1.

After a mean follow-up of 6.5 years (range: 3 to almost 10 years), during which the investigators were masked to the study outcomes, the DCCT ended in 1993, 1 year ahead of schedule. The independent Data, Safety and Quality Review Group had determined that efficacy had been demonstrated for both the primary prevention and secondary intervention cohorts. The main results were reported at a special symposium at the 1993 American Diabetes Association annual meeting and, subsequently, in the New England Journal of Medicine [16], in what has become the most frequently cited paper in diabetes.

\section{Interventions and conduct of the DCCT: insulin treatment directed at normoglycaemia}

In order to answer the questions posed by the National Commission, two studies were conducted within the DCCT. All participants were at least 13 years of age and less than 40 years of age at baseline (Table 1). The primary prevention question studied individuals with type 1 diabetes of 1 to 5 years' duration, no detectable retinopathy by stereoscopic fundus photography, and albumin excretion $<40 \mathrm{mg}$ per $24 \mathrm{~h}$, extrapolated from timed $4 \mathrm{~h}$ collections. The secondary intervention cohort could have diabetes duration from 1 to 15 years, had to have at least one microaneurysm in either eye, but less than severe non-proliferative retinopathy based on the modified Airlie House criteria (Early Treatment Diabetic Retinopathy Study [ETDRS]) [17], and less than $200 \mathrm{mg}$ albumin excretion per $24 \mathrm{~h}$.
Both primary prevention and secondary intervention cohorts were randomly assigned to either the 'standard' treatment or 'experimental' treatment. Keeping in mind that there was therapeutic equipoise during the conduct of the DCCT, standard treatment included one to two insulin injections per day with intermediate and rapid-acting insulins. Therapy was guided by limited urine or self-glucose monitoring with the goal of eliminating any symptoms of hyperglycaemia and freedom from frequent or severe hypoglycaemia, defined as hypoglycaemic episodes requiring assistance for treatment. If $\mathrm{HbA}_{1 \mathrm{c}}$ exceeded $13.1 \%$ (120 mmol $/ \mathrm{mol}$ ) (the mean $\mathrm{HbA}_{1 \mathrm{c}}$ of a sample of individuals with type 1 diabetes at the time +2 standard deviations [SD]), therapy was intensified. The mean $\mathrm{HbA}_{1 \mathrm{c}}$ level achieved in the standard-treatment group was $\sim 9 \%(75 \mathrm{mmol} / \mathrm{mol})$. In addition to the symptom-based goals shared with the standard-treatment group, experimental treatment aimed for glucose levels (determined by SMBG) that were $3.9-6.7 \mathrm{mmol} / \mathrm{l}$ pre-prandially, $<10 \mathrm{mmol} / \mathrm{l}$ postprandially and, as a weekly safety measure, $>3.6 \mathrm{mmol} / \mathrm{l}$ at 03:00 h. The $\mathrm{HbA}_{1 \mathrm{c}}$ goal was in the non-diabetic range $(<6.05 \%[<43 \mathrm{mmol} / \mathrm{mol}])$, based on the results of $13-$ to 39 -year-old non-diabetic volunteers in the DCCT clinics who had a mean $\mathrm{HbA}_{1 \mathrm{c}}$ of $5.05 \%$ (32 $\mathrm{mmol} / \mathrm{mol}$ ) plus $2 \mathrm{SD}$ $(1.0 \%$ [10.9 mmol $/ \mathrm{mol}])$.

Although the insulins available during the DCCT were limited compared with the large range of very-rapid-acting and very-long-acting analogue insulins now available, the investigators and participants were creative with the longacting (ultralente), intermediate-acting (NPH or lente) and short-acting (regular) insulins at their disposal. Efforts to match insulin delivery to insulin requirements were implemented with MDI ( $\geq 3$ daily injections) or CSII regimens with insulin pumps, based on participant choice. Every investigator was left to craft individual insulin delivery regimens for the 
Table 1 DCCT selected baseline participant characteristics

\begin{tabular}{|c|c|c|c|c|c|}
\hline \multirow[t]{2}{*}{ Characteristic } & \multirow[t]{2}{*}{ Total $n$} & \multicolumn{2}{|c|}{ Primary prevention } & \multicolumn{2}{|c|}{ Secondary intervention } \\
\hline & & Standard & Experimental & Standard & Experimental \\
\hline$N$ & 1441 & 378 & 348 & 352 & 363 \\
\hline Adolescents, $n(\%)^{\mathrm{a}}$ & $195(14)$ & $70(19)$ & $55(16)$ & $33(9)$ & $37(10)$ \\
\hline Age & & $26 \pm 8$ & $27 \pm 7$ & $27 \pm 7$ & $27 \pm 7$ \\
\hline Women, \% & & 46 & 51 & 46 & 47 \\
\hline Race, \% NHW & & 95 & 95 & 95 & 95 \\
\hline Duration, years & & $2.6 \pm 1.4$ & $2.6 \pm 1.4$ & $8.6 \pm 3.7$ & $8.9 \pm 3.8$ \\
\hline Body mass, $\%$ of ideal (SD) & & $103(14)$ & $103(13)$ & $104(13)$ & $105(12)$ \\
\hline \multicolumn{6}{|l|}{$\mathrm{HbA}_{1 \mathrm{c}}$} \\
\hline$\%$ & & $8.8 \pm 1.7$ & $8.8 \pm 1.6$ & $8.9 \pm 1.5$ & $9.0 \pm 1.5$ \\
\hline $\mathrm{mmol} / \mathrm{mol}$ & & $73 \pm 18.6$ & $73 \pm 17.5$ & $74 \pm 16.4$ & $75 \pm 16.4$ \\
\hline \multicolumn{6}{|l|}{ Retinopathy, \% } \\
\hline None & & 100 & 100 & 0 & 0 \\
\hline Very minimal to minimal NPDR & & & & 57.4 & 68.3 \\
\hline Moderate NPDR & & & & 31.6 & 22.3 \\
\hline Moderate to severe NPDR & & & & 10.5 & 8.9 \\
\hline \multicolumn{6}{|l|}{ Nephropathy } \\
\hline $\begin{array}{l}\text { Creatinine clearance, } \mathrm{ml} \mathrm{min}^{-1} \\
{[1.73 \mathrm{~m}]^{-2}}\end{array}$ & & $127 \pm 28$ & $128 \pm 30$ & $130 \pm 30$ & $128 \pm 31$ \\
\hline Albuminuria, $\mathrm{mg} / 24 \mathrm{~h}$ & & $12 \pm 8$ & $12 \pm 9$ & $19 \pm 24$ & $21 \pm 25$ \\
\hline
\end{tabular}

Data are presented as mean \pm SD unless stated otherwise

a Adolescent: aged $13-18$ years

NHW, non-Hispanic white; NPDR, non-proliferative diabetic retinopathy experimental-treatment-group volunteers. The insulin pumps at the time, which in retrospect seem dinosauric in their size and prehistoric in their simplicity, utilised principles of insulin delivery that remain to this day. Basal rates were designed to account for approximately $50 \%$ of total daily insulin, while preprandial doses, adjusted based on carbohydrate counting and preprandial glucose levels, made up the remainder. Most of the DCCT MDI regimens used ultralente or NPH/lente insulins once to twice per day as the basal insulin and shortacting insulin before meals; however, numerous other MDI regimens were used by the investigators to employ the limited insulins at hand most effectively [18]. The mean $\mathrm{HbA}_{1 \mathrm{c}}$ achieved in the intensive-treatment group was $\sim 7 \%$ (57 mmol/mol).

One of the major accomplishments of the DCCT was the exceptional retention of the participants and adherence to the protocol. Retention during the more than 9 years of the trial was virtually complete, with $99 \%$ of participants completing the study [16]. Adherence to the randomly assigned therapies was also remarkable, with $97 \%$ of time in the study spent on assigned therapy, even taking into account that women in the standard group changed (per protocol) to intensive therapy during preparation for and during pregnancy. The trivial loss to follow-up and lack of therapeutic crossover during the trial contributed to the independent Data, Safety and Quality Review Group being able to stop the study for efficacy 1 year ahead of schedule. The stable separation of $\mathrm{HbA}_{1 \mathrm{c}}$ levels between the treatment groups throughout DCCT (Fig. 2) set the stage for definitively addressing the 'glucose hypothesis' of diabetes complications.

\section{DCCT major results}

The main outcome of the DCCT, selected, in part, because of our ability to assess it using an established ordinal scale of severity, was retinopathy, with a 3 -step change based on the ETDRS scale [17] representing the primary outcome. Compared with the conventional treatment, experimental treatment reduced the development of retinopathy by $76 \%$ in the primary prevention cohort and reduced the progression of retinopathy by $54 \%$ in the secondary intervention cohort (Fig. 3) [16]. Similarly, the development and progression of nephropathy and neuropathy were reduced by $34-69 \%$. Of note, there was an early transient increase in mild retinopathy in the intensive-treatment group. The worsening retinopathy, confined almost entirely to the primary prevention cohort, was evident at the 6- and 12-month evaluations and the effect had 


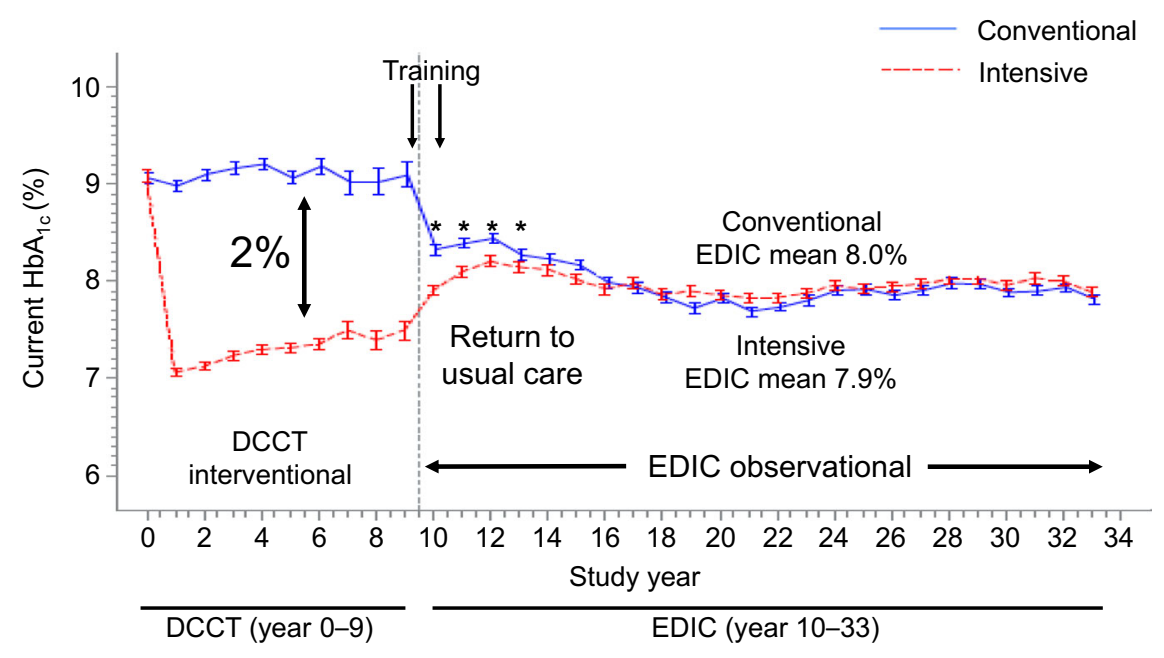

Fig. 2 Mean $\mathrm{HbA}_{1 \mathrm{c}}$ levels (with standard errors) during the DCCT and EDIC observational follow-up study. During DCCT, all $\mathrm{HbA}_{1 \mathrm{c}}$ results after baseline were significantly different between the intensive-treatment and conventional-treatment groups (difference in $\mathrm{HbA}_{1 \mathrm{c}}$ of $\sim 2 \%$ [22 $\mathrm{mmol} / \mathrm{mol}])$. At the end of the DCCT, the participants in the original conventional-treatment group were taught how to perform intensive therapy and all participants returned to their own healthcare providers for diabetes care. As a result, the difference in $\mathrm{HbA}_{1 \mathrm{c}}$ levels established

dissipated by 2 years, after which the benefit of intensive therapy emerged [19].

\section{Other results of the DCCT}

Although numerous presentations and publications described the myriad results of the DCCT, some of the most important addressed the following topics: the association of $\mathrm{HbA}_{1 \mathrm{c}}$ levels and complications [20,21]; the cost of experimental, now-called intensive, treatment and its projected impact on the burden of complications in the USA [22]; the effects of intensive therapy on endogenous insulin secretion, measured as residual C-peptide levels [23]; the adverse effects of intensive therapy, including hypoglycaemia [24] and a weight gain in the first year of therapy of $5.1 \pm 4.6 \mathrm{~kg}$ compared with $2.4 \pm$ $3.7 \mathrm{~kg}$ in the conventional-treatment group [25]; and, because of the recognised increased risk for hypoglycaemia, the cognitive status of the treatment groups over time [26]. A brief description of these topics follows.

Beyond the effects of experimental vs standard treatment on diabetes complications, which was directly studied in the DCCT, secondary analyses examined the relationship between the $\mathrm{HbA}_{1 \mathrm{c}}$ levels achieved over time and complications $[20,21]$. The association between mean $\mathrm{HbA}_{1 \mathrm{c}}$ levels and outcomes over time was strong and continuous, without any threshold, down to non-diabetic levels (Fig. $4 a)$. Virtually all of the beneficial effects of intensive therapy were statistically explained by the separation in $\mathrm{HbA}_{1 \mathrm{c}}$ levels between the treatment groups. The risk for during the DCCT decreased and disappeared by 4 years after DCCTend $(* p<0.05$ between treatment groups during the first 4 years of the EDIC study). To convert values for $\mathrm{HbA}_{1 \mathrm{c}}$ in $\%$ into $\mathrm{mmol} / \mathrm{mol}$, subtract 2.15 and multiply by 10.929. (C) American Diabetes Association 2016, adapted from [50]. Copyright and all rights reserved. Material from this publication has been used with the permission of American Diabetes Association. This figure is available as part of a downloadable slideset

hypoglycaemia increased with lower $\mathrm{HbA}_{1 \mathrm{c}}$ levels (Fig. $4 \mathrm{~b})$. The economic modelling predicted large human savings, with substantial reductions in vision loss, kidney failure and amputations and an accompanying reduction in medical costs, even taking into account the additional lifelong expense of intensive therapy [22].

Three hundred and three DCCT participants, among the 855 with $1-5$ years of diabetes duration, had residual stimulated C-peptide at baseline ('responders' had 0.2 $0.5 \mathrm{pmol} / \mathrm{ml} \mathrm{C}$-peptide after an oral carbohydrate challenge; those with levels $>0.5 \mathrm{pmol} / \mathrm{ml}$ had been excluded from the DCCT during screening). Approximately, one-half were randomly assigned either to experimental or standard treatment. In these responders, intensive treatment reduced the decline in endogenous insulin secretion by $57 \%$ [23]. Preserved insulin secretion, even at low levels, both at baseline [23] and during the study [27], proved to be clinically significant. At baseline, responders had significantly lower $\mathrm{HbA}_{1 \mathrm{c}}$ levels compared with non-responders (8.3\% vs $9.4 \%$ [67 mmol/mol vs $79 \mathrm{mmol} / \mathrm{mol}$ ], respectively). Among those participants randomly assigned to intensive therapy, responders had $\mathrm{HbA}_{1 \mathrm{c}}$ levels of $6.7 \%(50 \mathrm{mmol} / \mathrm{mol})$ vs $7.2 \%(55 \mathrm{mmol} / \mathrm{mol})$ in non-responders at 1 year, and $6.9 \%(52 \mathrm{mmol} / \mathrm{mol})$ vs $7.5 \%$ (58 $\mathrm{mmol} / \mathrm{mol})$ over the first seven years of the DCCT [27]. Responders also used lower insulin doses and had less frequent hypoglycaemia compared with non-responders. Finally, within the intensive-treatment group, responders had a $50 \%$ lower rate of retinopathy compared with the participants in whom Cpeptide secretion was lost. 


Retinopathy
Development of 3-step
Progression by 3-ste
Prevent SNPDR
Nephropathy
Microalbuminuria
Microalbuminuria
Macroalbuminuria
Macroalbuminuria
Neuropathy
Clinical neuropathy
Clinical neuropathy

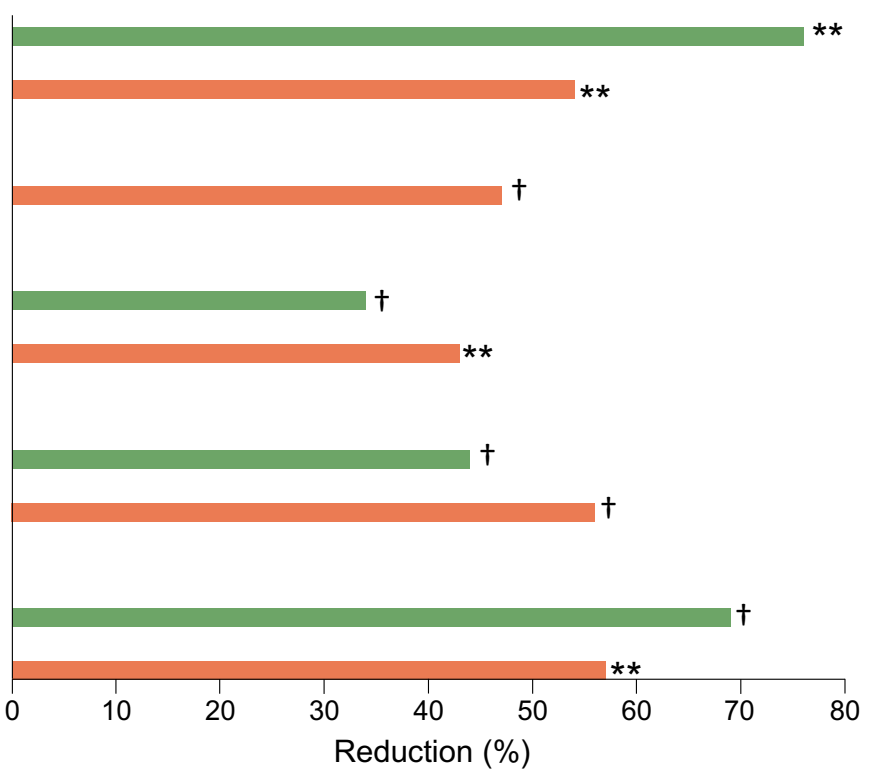

INT

CONV

Rates (per

100 patient-years)

1.2

4.7

3.7

7.8

1.1

2.4

2.2

3.4

3.6

0.2

0.3

0.6

1.4

Per cent with neuropathy

3.1

9.8

7.0

16.1
Fig. 3 Reduction in the risk of complications during the DCCT with intensive vs conventional treatment for the primary prevention (green bar) and secondary intervention (orange bar) cohorts. The development of retinopathy (primary prevention) was defined as $\geq 3$-step sustained retinopathy change from baseline based on the ETDRS scale, and the progression of retinopathy (secondary intervention) was defined as $\geq 3$ step progression. Nephropathy development was defined as microalbuminuria and macroalbuminuria $(24 \mathrm{~h}$ albumin excretion of $\geq 40 \mathrm{mg} / 24 \mathrm{~h}$ and $>300 \mathrm{mg} / 24 \mathrm{~h}$, respectively, calculated from a timed $4 \mathrm{~h}$ collection). Clinical neuropathy was defined as a clinical exam consistent with distal sensorimotor neuropathy plus either abnormal nerve

Hypoglycaemia was recognised early on as the major risk and potential safety problem associated with experimental treatment [24]. All episodes of hypoglycaemia, including severe episodes, defined as those requiring assistance to treat, were increased threefold with experimental vs standard treatment (61 episodes vs 19 episodes per 100 patient-years). Much of the risk for hypoglycaemia was confined to a subset of experimental-group participants who suffered repeated episodes. Of note, despite concern regarding the potential impact of hypoglycaemia on cognitive function, the comprehensive neurocognitive testing performed as often as four times over the course of the DCCT did not reveal any obvious adverse effects on cognition [26]. The only statistically significant difference between the treatment groups was faster motor speed in the experimental- vs the conventionaltreatment group, which was related to $\mathrm{HbA}_{1 \mathrm{c}}$ levels and likely a reflection of less neuropathy in the experimental-treatment group. Finally, whether the burden of intensive treatment (with more frequent self-monitoring and injections, use of insulin pumps and increased hypoglycaemia) would translate into reduced quality of life $(\mathrm{QoL})$ was of concern. However, measurements of QoL revealed no significant differences between the treatment groups [28]. conduction in $\geq 2$ peripheral nerves or unequivocally abnormal autonomic nerve testing. Other than for neuropathy, the rate per 100 patient-years and the percentage reductions in risk (hazard rate) for intensive vs conventional treatment were calculated using the proportional hazards model with adjustment for baseline values; for neuropathy, the simple percentages with neuropathy are shown and the percentage risk reduction obtained from a log risk model. CONV, conventional treatment; INT, intensive treatment; SNPDR, severe non-proliferative diabetic retinopathy. ${ }^{*} p<<0.002 ;{ }^{\dagger} p<0.04$; analysed by two-tailed rank-sum test. Data from [49]. This figure is available as part of a downloadable slideset

\section{Epidemiology of Diabetes Interventions and Complications study: observational follow-up of the DCCT cohort}

In the wake of the successful completion of the DCCT, plans for continued follow-up of the loyal DCCT cohort were developed and funded by the NIDDK [29]. Before beginning the Epidemiology of Diabetes Interventions and Complications (EDIC) observational study in 1994 (Fig. 1), the original conventional-treatment group was taught intensive therapy and all of the participants were returned to their own healthcare providers for diabetes care. Predictably, these steps resulted in the narrowing and eventual effacement of the intertreatment group differences in $\mathrm{HbA}_{1 \mathrm{c}}$ over time (Fig. 2). Ninety-six per cent $(n=1394)$ of the surviving DCCT cohort joined the EDIC study, which will have continued, as of 2021, for 28 years, for a total DCCT/EDIC mean study period of 35 years (range 33-38 years). The initial major goals of the EDIC study were to determine the longer-term effects of the original interventions on more advanced microvascular complications and on CVD and mortality. These could not be determined during DCCT owing to the limited number of events in the relatively young DCCT cohort with limited 

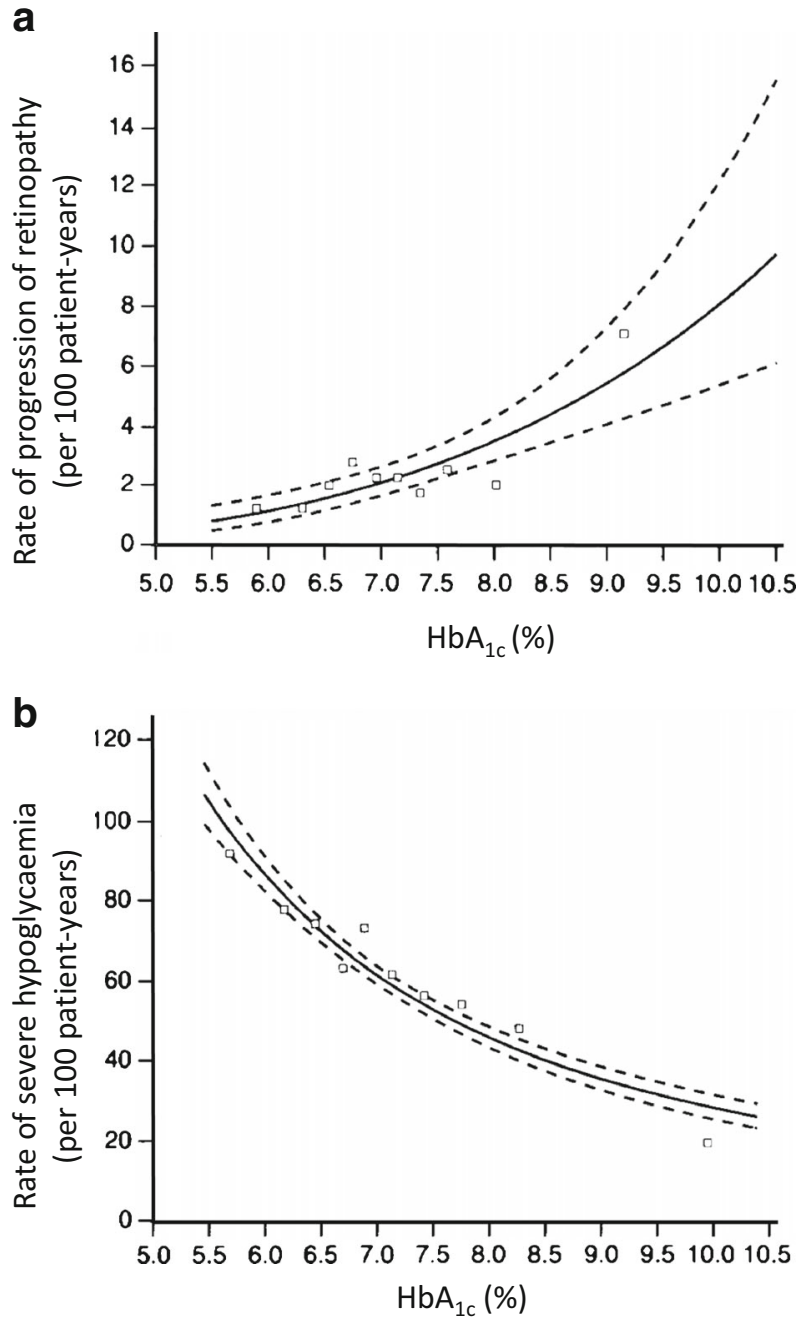

Fig. 4 Relationship between mean $\mathrm{HbA}_{1 \mathrm{c}}$ levels and (a) rate of retinopathy progression, based on 3-step retinopathy change (ETDRS scale) from baseline status in the intensive-treatment group, or (b) rate of severe hypoglycaemia. Mean $\mathrm{HbA}_{1 \mathrm{c}}$ (solid line) in (a) is based on values obtained every 6 months and, in (b), on monthly values. Dashed line, 95\% confidence intervals. To convert values for $\mathrm{HbA}_{1 \mathrm{c}}$ in $\%$ into $\mathrm{mmol} / \mathrm{mol}$, subtract 2.15 and multiply by 10.929 . Adapted from [16], reprinted with permission from the Massachusetts Medical Society. This figure is available as part of a downloadable slideset

diabetes duration. During the EDIC follow-up, interventions changed in parallel with community-based changes in the USA and Canada. Virtually all of the EDIC cohort use new insulins, including long-acting analogues in MDI regimens and very-rapid-acting analogues in MDI and pump therapy.

The results of EDIC to date have been reported in more than 200 publications. The most prominent findings (Table 2) include: (1) the long-term benefit of intensive therapy compared with conventional therapy on advanced microvascular disease [30,31], a 57\% reduction in CVD events [32] and a $33 \%$ reduction in the rate of mortality $[33,34]$; (2) the relationship of prior $\mathrm{HbA}_{1 \mathrm{c}}$ levels on complications, including clinically severe complications [35,36], a phenomenon called 'metabolic memory' [37, 38]; and (3) the long-term effects of
DCCT interventions and associated $\mathrm{HbA}_{1 \mathrm{c}}$ levels on morerecently recognised complications of diabetes, such as cheiroarthropathy [39] and hearing loss [40]. Metabolic memory was discovered only because of the purposeful crossover of the conventional-treatment group to intensive therapy at DCCT-end and the resultant disappearance of the $\mathrm{HbA}_{1 \mathrm{c}}$ differences between the original treatment groups during EDIC. Based on the strong association of all complications with $\mathrm{HbA}_{1 \mathrm{c}}$ levels $[20,21]$, we logically expected that the rates of complications would equalise between the two treatment groups during EDIC. However, within the first 4 years of the EDIC study, the rates of retinopathy and nephropathy continued to diverge, with the conventional-treatment group suffering an increasing rate of these complications as compared with the original intensive-treatment group. This pattern continued for approximately 10 years, after which 'metabolic amnesia' began.

An inverse association between the occurrence of severe hypoglycaemia and $\mathrm{HbA}_{1 \mathrm{c}}$ was demonstrated during the DCCT study (Fig. 4b) [16, 24]; therefore, during EDIC, when $\mathrm{HbA}_{1 \mathrm{c}}$ rose in the original intensive-treatment group and fell in the original conventional-treatment group, the rates of severe hypoglycaemia were anticipated to equalise across the two groups. The most-recent analyses show that this is the case [41]. The original rates of severe hypoglycaemia have fallen from 61.2 episodes per 100 patient-years during the DCCT to 40.8 episodes per 100 patient-years during the EDIC study in the original intensive-treatment group, and have risen from 18.7 to 36.6 episodes per 100 patient-years in the original conventional-treatment group.

\section{Mechanisms}

Neither the DCCT nor the EDIC study was designed to determine specific mechanisms behind the development of diabetes complications. Nevertheless, ongoing collaborations have identified potential underlying mechanisms of microvascular and cardiovascular complications of diabetes, building on prior insights related to glycaemic control and complications. Several of the prominent findings include the major role of hyperglycaemia, not only in the more diabetes-specific microvascular complications, but in cardiovascular complications where $\mathrm{HbA}_{1 \mathrm{c}}$ has been identified as the second most powerful risk factor after age in this relatively young population [42]. In addition, post-translationally modified proteins, such as oxidised lipoproteins [43] and modified lipoproteins in immune complexes [44], have been shown to be potential links between $\mathrm{HbA}_{1 \mathrm{c}}$ levels and CVD. The formation of advanced glycation end-products in skin collagen [45], presumably reflecting similar changes in other connective tissues that turn over very slowly, may explain the durable effect of previous glycaemic levels on complications, i.e. 
Table 2 Summary of major results from the EDIC study (1994-present)

\begin{tabular}{|c|c|c|}
\hline Outcome measure & Major findings & Reference \\
\hline \multicolumn{3}{|c|}{ Advanced microvascular complications (INT vs CONV treatment) } \\
\hline Retinopathy & Reduced eye surgery by $48 \%$ & {$[30]$} \\
\hline Nephropathy & 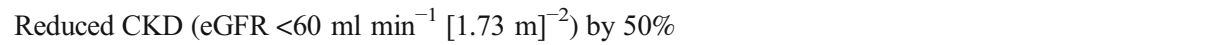 & [31] \\
\hline \multicolumn{3}{|c|}{ Cardiovascular outcomes (INT vs CONV treatment) } \\
\hline $\begin{array}{l}\text { Major adverse } \\
\text { cardiovascular events }\end{array}$ & Reduced by $57 \%$ after 17 years & {$[32]$} \\
\hline Blood glucose as a risk factor & $\mathrm{HbA}_{1 \mathrm{c}}$ is the most powerful risk factor after age & {$[42]$} \\
\hline $\begin{array}{l}\text { Mortality (INT vs CONV } \\
\text { treatment) }\end{array}$ & $\begin{array}{l}\text { Reduced mortality by } 33 \% \text {; standardised mortality rates no different in the INT group vs non-diabetic US } \\
\text { population }\end{array}$ & {$[33,34]$} \\
\hline $\begin{array}{l}\text { Effects of mean blood glucose } \\
\text { levels }\end{array}$ & Mean $\mathrm{HbA}_{1 \mathrm{c}}$ during the $\mathrm{DCCT}$ remained tightly associated with risk for complications & {$[35,36]$} \\
\hline Metabolic memory & $\begin{array}{l}\text { Despite narrowing of differences in } \mathrm{HbA}_{1 \mathrm{c}} \text { during EDIC, effects of glycaemic exposure during the DCCT } \\
\text { persisted for } \sim 10 \text { years }\end{array}$ & {$[37,38]$} \\
\hline
\end{tabular}

CKD, chronic kidney disease; CONV, conventional (previously 'standard') treatment; INT, intensive (previously termed 'experimental') treatment

metabolic memory. Epigenetic changes associated with glycation have been invoked as another potential mechanism to explain metabolic memory [46].

\section{Challenges and the future}

The DCCT used insulins, and devices to deliver them, that now seem primitive; however, the mean $\mathrm{HbA}_{1 \mathrm{c}}$ of $7 \%$ (53 $\mathrm{mmol} / \mathrm{mol}$ ) achieved and maintained with intensive therapy over a mean 6.5 years in the DCCT has not been substantially improved in more-recent short-term studies using modern-day insulin analogues delivered with MDI regimens or with sophisticated pumps guided by continuous glucose monitoring [47, 48]. The major improvements achieved to date with new insulins and devices relate to the ease of treatment and reduced risk of hypoglycaemia. The ongoing challenge remains to provide insulin therapy with the goal of achieving and maintaining $\mathrm{HbA}_{1 \mathrm{c}}$ levels as close to the nondiabetic range as safely possible. It is noteworthy that the highly committed and trained DCCT/EDIC population, now treated in the community, has not maintained, on average, the glycaemic levels that they proved to be beneficial. The advances in available insulins and in the means to deliver them should make intensive therapy more widely available and convenient for all patients with type 1 diabetes. Whether biological approaches to achieve this goal, such as immunoprotected islet transplantation or amelioration of the autoimmune attack on islets, will eventually supplant the need to treat with insulin remains to be seen. For now, we need to continue to improve insulin therapy.

The DCCT/EDIC cohort is approaching a mean age of 63 years (range: 43-76, years). With the prospect of continued funding and taking advantage of the extraordinary phenotyping and genotyping of the cohort over a total of more than 38 years to date, we hope to study the clinical course of people with type 1 diabetes as they age during the modern-day period of intensive therapy.

\section{Conclusions}

The discovery of insulin by Banting, Best, Collip and Macleod established its life-saving power. DCCT/EDIC and a large community of investigators have shown how to use insulin to its best advantage, not only preserving life but also improving QoL by reducing vision loss, kidney failure, CVD and other complications previously considered inevitable.

Supplementary Information The online version of this article (https:// doi.org/10.1007/s00125-021-05397-4) contains a slideset of the figures for download.

Acknowledgements The DCCT/EDIC Research Group and the diabetes community owe an immeasurable debt to the 1441 loyal DCCT/EDIC participants and their families who have made the study possible and provided a brighter future for all people with diabetes.

Author's relationships and activities The author declares that there are no relationships or activities that might bias, or be perceived to bias, this work.

Contribution statement $\mathrm{DMN}$ is solely responsible for the content of the paper.

\section{References}

1. Banting FG, Best CH, Collip JB, Campbell WR, Fletcher AA (1922) Pancreatic extracts in the treatment of diabetes mellitus. Can Med Assoc J 12:141-146 
2. National Diabetes Data Group (1979) Classification and diagnosis of diabetes mellitus and other categories of glucose intolerance. Diabetes 28:1039-1057. https://doi.org/10.2337/diab.28.12.1039

3. Deckert T, Poulsen JE, Larsen M (1978) The prognosis of insulin dependent diabetes mellitus. Diabetologia 14:363-370. https://doi. org/10.1007/BF01228130

4. Siperstein MD, Unger RH, Madison LL (1968) Studies of muscle capillary basement membranes in normal subjects, diabetic, and prediabetic patients. J Clin Invest 47(9):1973-1999. https://doi. org/10.1172/JCI105886

5. Cahill GF, Etzwiler DF, Freinkel N (1976) "Control" and diabetes. N Engl J Med 294:1004-1005. https://doi.org/10.1056/ NEJM197604292941811

6. Nathan DM, Singer DE, Godine JE, Harrington CH, Perlmuter LC (1986) Retinopathy in older type II diabetics: association with glucose control. Diabetes 35:797-801. https://doi.org/10.2337/ diab.35.7.797

7. Schiffrin A, Belmonte M (1982) Multiple daily self-glucose monitoring; its essential role in long-term glucose control in insulindependent diabetic patients treated with pump and multiple subcutaneous injections. Diabetes Care 5:479-484. https://doi.org/10. 2337/diacare.5.5.479

8. Kroc Collaborative Study Group (1984) Blood glucose control and the evolution of diabetic retinopathy and albuminuria: a preliminary multicenter trial. N Engl J Med 311:365-372. https://doi.org/10. 1056/NEJM198408093110604

9. Dahl-Jorgensen K, Brinchmann-Hansen O, Hanssen KF, Sandvik L, Aagenaes O (1985) Aker Diabetes Group. Rapid tightening of blood glucose control leads to transient deterioration of retinopathy in insulin dependent diabetes mellitus: the Oslo Study. BMJ 290: 811-815. https://doi.org/10.1136/bmj.290.6471.811

10. Lauritzen T, Frost-Larsen K, Larsen K, Larsen H-W, Deckert T (1983) The Steno Study Group. Effect of one year of near-normal blood glucose levels on retinopathy in insulin-dependent diabetics. Lancet i:200-204

11. Holman RR, Dornan TL, Mayon-White V et al (1983) Prevention of deterioration of renal and sensor-nerve function by more intensive management of insulin- dependent diabetic patients. Lancet 1(8318):204-208. https://doi.org/10.1016/s0140-6736(83)92586-2

12. United States National Commission on Diabetes (1976) The LongRange Plan to Combat Diabetes 1976 Update. (DHEW 76-1018). U.S. Department of Health, Education, and Welfare, Public Health Service, National Institutes of Health, Bethesda, MD

13. National Institutes of Health Diabetes Mellitus Coordinating Committee (1979) Report to the Director, National Institutes of Health on Progress towards implementation of the recommendations of the National Commission on Diabetes and the National Diabetes Advisory Board: 1979. NIH Publication No. 80-2170. U.S. Department of Health and Human Services, Public Health Service, National Institutes of Health, Bethesda, MD

14. The DCCT Research Group (1987) Diabetes Control and Complications Trial (DCCT): results of feasibility study. Diabetes Care 10:1-19. https://doi.org/10.2337/diacare.10.1.1

15. DCCT Research Group (1990) Diabetes Control and Complications Trial (DCCT): update. Diabetes Care 13:427-433. https://doi.org/10.2337/diacare.13.4.427

16. Diabetes Control and Complications Trial Research Group (1993) The effect of intensive diabetes treatment on the development and progression of long-term complications in insulin-dependent diabetes mellitus: the Diabetes Control and Complications Trial. N Engl J Med 329:978-986

17. Early Treatment Diabetic Retinopathy Study (ETDRS) (1981) Manual of operations. University of Maryland Press, Baltimore

18. Diabetes Control and Complications Trial Research Group (1995) Implementation of treatment protocols in the Diabetes Control and
Complications Trial. Diabetes Care 18:361-376. https://doi.org/10. 2337/diacare.18.3.361

19. The Diabetes Control and Complications Trial Research Group (1995) The effect of intensive diabetes treatment on the progression of diabetic retinopathy in insulin-dependent diabetes mellitus. The Diabetes Control and Complications Trial. Arch Ophthalmol 113: 36-51. https://doi.org/10.1001/archopht.1995.01100010038019

20. The Diabetes Control and Complications Trial Research Group (1995) The relationship of glycemic exposure $\left(\mathrm{HbA}_{1 \mathrm{c}}\right)$ to the risk of development and progression of retinopathy in the Diabetes Control and Complications Trial. Diabetes 44:968-983. https:// doi.org/10.2337/diab.44.8.968

21. The Diabetes Control and Complications Trial Research Group (1996) The absence of a glycemic threshold for the development of long-term complications: the perspective of the Diabetes Control and Complications Trial. Diabetes 45:1289-1298. https://doi.org/ 10.2337/diab.45.10.1289

22. The Diabetes Control and Complications Trial Research Group (1996) Lifetime benefits and costs of intensive therapy as practice in the Diabetes Control and Complications Trial. JAMA 276:14091415. https://doi.org/10.1001/jama.1996.03540170053032

23. The Diabetes Control and Complications Trial Research Group (1998) Effect of intensive therapy on residual $\beta$-cell function in patients with type 1 diabetes in the Diabetes Control and Complications Trial. A randomized, controlled trial. Ann Intern Med 128:517-523. https://doi.org/10.7326/0003-4819-128-7199804010-00001

24. The Diabetes Control and Complications Trial Research Group (1997) Hypoglycemia in the Diabetes Control and Complications Trial. Diabetes 46:271-286. https://doi.org/10.2337/diab.46.2.271

25. The DCCT Research Group (1988) Weight gain associated with intensive therapy in the Diabetes Control and Complications Trial. Diabetes Care 11:567-573. https://doi.org/10.2337/diacare. 11.7.567

26. The Diabetes Control and Complications Trial Research Group (1996) Effects of intensive diabetes therapy on neuropsychological function in adults in the Diabetes Control and Complications Trial. Ann Intern Med 124:379-388. https://doi.org/10.7326/0003-4819124-4-199602150-00001

27. Lachin JM, McGee P, Palmer JP, for the DCCT/EDIC Research Group (2014) Impact of C-peptide preservation on metabolic and clinical outcomes in the diabetes control and complications trial. Diabetes. 63:739-748. https://doi.org/10.2337/db13-0881

28. The Diabetes Control and Complications Trial Research Group (1996) Influence of intensive diabetes treatment on quality-of-life outcomes in the Diabetes Control and Complications Trial. Diabetes Care 19:195-203. https://doi.org/10.2337/diacare.19.3. 195

29. Epidemiology of Diabetes Interventions and Complications (EDIC) Research Group (1999) Epidemiology of Diabetes Interventions and Complications (EDIC): design, implementation, and preliminary results of a long-term follow-up of the Diabetes Control and Complications Trial cohort. Diabetes Care 22:99-111. https://doi. org/10.2337/diacare.22.1.99

30. The DCCT/EDIC Research Group (2015) Intensive diabetes therapy and ocular surgery in type 1 diabetes. N Engl J Med 372:17221733. https://doi.org/10.1056/NEJMoa1409463

31. The DCCT/EDIC Research Group (2011) Intensive diabetes therapy and glomerular filtration rate in type 1 diabetes. N Engl J Med 365:2366-2376. https://doi.org/10.1056/NEJMoa1111732

32. The Diabetes Control and Complications Trial/ Epidemiology of Diabetes Interventions and Complications (DCCT/EDIC) Study Research Group (2005) Intensive diabetes treatment and cardiovascular disease in type 1 diabetes mellitus. N Engl J Med 353:26432653. https://doi.org/10.1056/NEJMoa052187 
33. Writing Group for the DCCT/EDIC Research Group (2015) Association between 7 years of intensive treatment and long-term mortality. JAMA 313:45-53. https://doi.org/10.1001/jama.2014. 16107

34. The Diabetes Control and Complications Trial (DCCT)/ Epidemiology of Diabetes Interventions and Complications (EDIC) Study Research Group (2016) Mortality in type 1 diabetes in the DCCT/EDIC versus the general population. Diabetes Care 39:1378-1383. https://doi.org/10.2337/dc15-2399

35. Hainsworth DP, Bebu I, Aiello LP et al (2019) Risk factors for retinopathy in type 1 diabetes: the DCCT/EDIC study. Diabetes Care 42:875-882. https://doi.org/10.2337/dc18-2308

36. Perkins BA, Bebu I, DeBoer IH et al (2019) Risk factors for kidney disease in type 1 diabetes. Diabetes Care 42:883-890. https://doi. org $/ 10.2337 / \mathrm{dc} 18-2062$

37. The Diabetes Control and Complications Trial/ Epidemiology of Diabetes Interventions and Complications Research Group (2000) Retinopathy and nephropathy in patients with type 1 diabetes four years after a trial of intensive therapy. N Engl J Med 342:381-389. https://doi.org/10.1056/NEJM200002103420603

38. Writing Team for the Diabetes Control and Complications Trial /Epidemiology of Diabetes Interventions and Complications Research Group (2003) Sustained effect of intensive treatment of type 1 diabetes mellitus on development and progression of diabetic nephropathy: the Epidemiology of Diabetes Interventions and Complications (EDIC) study. JAMA 290:2159-2167. https://doi. org/10.1001/jama.290.16.2159

39. Larkin ME, Barnie A, Braffett BH et al (2014) Musculoskeletal complications in type 1 diabetes. Diabetes Care 37:1863-1869. https://doi.org/10.2337/dc13-2361

40. Schade DS, Lorenzi GM, Braffett BH et al (2018) Hearing impairment and type 1 diabetes in the Diabetes Control and Complications Trial/Epidemiology of Diabetes Interventions and Complications (DCCT/EDIC) cohort. Diabetes Care 41:2495-2501. https://doi. org $10.2337 /$ dc $18-0625$

41. Gubitosi-Klug RA, Braffett BH, White NH et al (2017) Risk of severe hypoglycemia in type 1 diabetes over 30 years of followup in the DCCT/EDIC study. Diabetes Care 40:1010-1016. https:// doi.org/10.2337/dc16-2723

42. Bebu I, Schade D, Braffett B et al (2020) Risk factors for first and subsequent CVD events in type 1 diabetes: the DCCT/EDIC study. Diabetes Care 43:867-874. https://doi.org/10.2337/dc19-2292
43. Lopes-Virella MF, Carter RE, Baker NL, Lachin J, Virella G (2012) High levels of oxidized LDL in circulating immune complexes are associated with increased odds of developing abnormal albuminuria in type 1 diabetes. Nephrol Dial Transplant 27:1416-1423. https:// doi.org/10.1093/ndt/gfr454

44. Lopes-Virella MF, Bebu I, Hunt KJ et al (2019) Immune complexes and the risk of CVD in type 1 diabetes. Diabetes 68:1853-1860. https://doi.org/10.2337/db19-0358

45. Genuth S, Sun W, Cleary P et al (2005) Glycation and carboxymethyllysine levels in skin collagen predict the risk of future 10-year progression of diabetic retinopathy and nephropathy in the Diabetes Control and Complications Trial and Epidemiology of Diabetes Interventions and Complications participants with type 1 diabetes. Diabetes 54:3103-3111

46. Chen Z, Miao F, Paterson AD et al (2016) Epigenomic profiling reveals an association between persistent methylation and metabolic memory in the DCCT/EDIC type 1 diabetes cohort. Proc Natl Acad Sci USA 113:E3002-E3011

47. Bergenstal RM, Tamborlane WV, Ahmann A et al (2010) STAR 3 Study Group. Effectiveness of sensor-augmented insulin-pump therapy in type 1 diabetes. N Engl J Med 363:311-320. https:// doi.org/10.1056/NEJMoa1002853

48. Beck RW, Riddlesworth TD, Ruedy KJ et al (2017) Effect of initiating use of an insulin pump in adults with type 1 diabetes using multiple daily insulin injections and continuous glucose monitoring (DIAMOND): a multicentre, randomized controlled trial. Lancet Diabetes Endocrinol 9:700-708

49. Nathan DM, Bayless M, Cleary P et al (2013) Diabetes Control and Complications Trial/Epidemiology of Diabetes Interventions and Complications study at 30 years: advances and complications. Diabetes 62:3976-3986. https://doi.org/10.2337/db13-1093

50. The Writing Group for the DCCT/EDIC Research Group (2016) Coprogression of cardiovascular risk factors in type 1 diabetes during 30 years of follow-up in the DCCT/EDIC study. Diabetes Care 39(9):1621-1630. https://doi.org/10.2337/dc16-0502

Publisher's note Springer Nature remains neutral with regard to jurisdictional claims in published maps and institutional affiliations. 